\title{
RADIOTHERAPY FOR MALIGNANT MELANOMA OF THE CHOROID*
}

BY

\author{
H. B. STALLARD \\ London
}

IT is evident from current ophthalmic literature that there is still an unawareness of the possibility and the value of radiotherapy for some patients with malignant melanoma of the choroid, despite the publication of several papers and lectures about this matter. So this paper is submitted as a reasonable excuse for publishing the results of the first hundred patients with malignant melanoma of the choroid treated by radio-active applicators between 1939 and 1964 (99 by ${ }^{60} \mathrm{Co}$ applicators and one by radon seeds in 1939).

The presence of malignant melanoma of the choroid, whether in an only eye or when the other eye is blind or almost so from either disease or amblyopia and in rare cases when this tumour is bilateral, would naturally incite even the most orthodox-minded surgeon to seek an alternative treatment to the tragic consequence of excision. It is fortunate that freedom of thought in medicine still allows us to challenge accepted and time-honoured therapeutic procedures and beliefs. Among these has been the authoritative statement that malignant melanomata are radioresistant for irradiation. This depressing attitude is untrue, for a number of malignant melanomata of the choroid are in fact radiosensitive and become reduced to a flat, pigment-stippled scar (Fig. 1). The effective application of radiotherapeutic

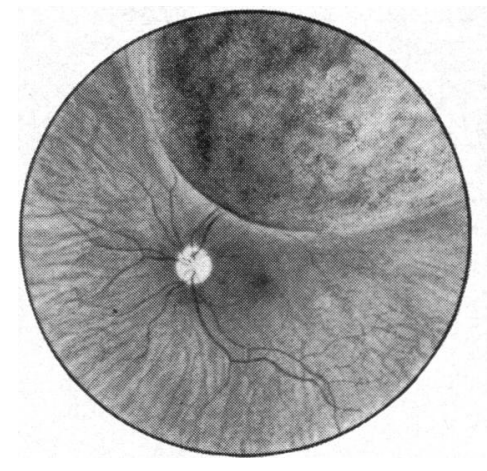

15.12 .60

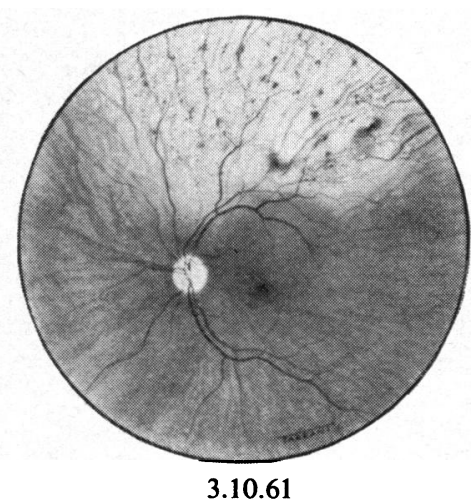

3.10.61

FIG. 1.-Malignant melanoma before and after radiotherapy, showing flat, pigment-stippled scar.

* Received for publication June 21, 1965. 
technique to date has been by means of either radium or ${ }^{60} \mathrm{Co}$-loaded applicators, circular, crescentic, and semi-circular, sutured to the sclera, exactly overlapping the base of the neoplasm by at least $1 \mathrm{~mm}$. (Fig. 2). The dose delivered to the base of the neoplasm and to its summit is considerably higher than can be administered by ${ }^{60} \mathrm{Co}$ beam or teletherapy, from which doses larger than $4000 \mathrm{r}$ at the choroid cause serious damage to the eye, particularly the cornea and lens. Indeed, in the two patients in whom it was tried ${ }^{60} \mathrm{Co}$ beam therapy failed. The successes following the use of radio-active applicators have been encouraging.

The diameter of the base of the neoplasm may be measured with fair accuracy by an ophthalmoscopic graticule. Measurements taken of the heights of malignant melanomata after excision of an eye show that before the neoplasm has burst through Bruch's membrane the average is one-third to one-half of the diameter of the base.

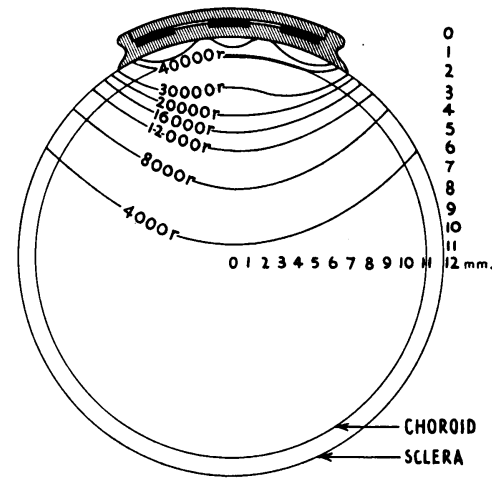

FIG. 2.-Radiotherapeutic technique: isodose for $10-\mathrm{mm}$. diameter $1.84 \mathrm{mc}$. ${ }^{60} \mathrm{Co}$ applicator for 14 days.

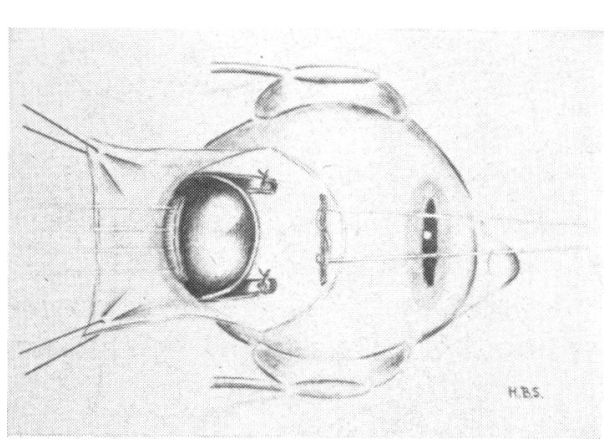

FIG. 3.-Radio-active applicator placed over marked site and sutured to sclera.

\section{Technique}

The technique of application of a radio-active applicator is simple. The sclera is exposed over the site of the neoplasm, which is marked by catholysis punctures $1 \mathrm{~mm}$. or a little more wide of the neoplasm. Obviously no attempt is made to mark the posterior limit of the neoplasm when it is near the macula, is adjacent to the optic disc, and when its prominence would conceal a catholysis puncture. The radio-active applicator of appropriate size, loading, and shape is placed over the marked site and sutured to the sclera with two silk stitches which pass through the holes in its lugs (Fig. 3).

\section{Dose}

The $r$ dose is still empirical and under trial. Up to the present it has been impossible to assess precisely the $r$ dose throughout neoplasms which are not consistently symmetrical in shape. Calculations from isodose eurves suggest that the majority (63 out of 100) received between 7,000 and 14,000 $\mathrm{r}$ at the summit and between 20,000 and 40,000 at the base in 7 to 14 days respectively (Table I). The 10 patients who received $28,000 \mathrm{r}$ at the summit and $80,000 \mathrm{r}$ at the base of the neoplasm had two applications. One patient, a failure, received three applications 
of $42,000 \mathrm{r}$ at the summit of the neoplasm and 120,000 $\mathrm{r}$ at its base (Table I). Of the 69 successes 55 had a single radio-active application and 14 had two treatments (Table II).

TABLE I

r Dose

\begin{tabular}{c|c|c|c|c}
\hline \multicolumn{2}{c|}{ r Dose } & \multirow{2}{*}{ Successes } & Failures & $\begin{array}{c}\text { Uncertain } \\
\text { to Date }\end{array}$ \\
\hline Base & Summit & & & 6 \\
\hline 20,000 & 7,000 & 5 & & \\
\hline 30,000 & 10,000 & 20 & 1 & 3 \\
\hline 40,000 & 14,000 & 29 & 8 & \\
\hline 50,000 & 17,000 & 2 & & \\
\hline 60,000 & 21,000 & 3 & & \\
\hline 70,000 & 24,000 & 1 & 5 & \\
\hline 80,000 & 28,000 & 9 & 1 & \\
\hline 120,000 & 42,000 & & 1 & \\
\hline & & 69 & 16 & \\
\hline
\end{tabular}

TABLE II

Number of APPlications

\begin{tabular}{c|c|c|c}
\hline $\begin{array}{c}\text { No. of } \\
\text { Applications }\end{array}$ & Successes & Failures & $\begin{array}{c}\text { Uncertain } \\
\text { to Date }\end{array}$ \\
\hline 1 & 55 & 9 & 6 \\
\hline 2 & 14 & 6 & 3 \\
\hline 3 & 69 & 16 & 9 \\
\hline Total & & 16 & \\
\hline
\end{tabular}

\section{Sex}

In this series of 100 patients 55 are males and 45 females. Among the 69 successes 35 are women and 34 men. Of the failures requiring excision of the eye 6 are women and 10 are men, and of the 6 patients who have died of metastatic deposits 2 were women and 4 were men (Table III). From these statistics it is evident that the prognosis is better in women than in men, and this is particularly so in the fourth and fifth decades of life. Indeed, MacRae (1953) has stated that women tend to develop malignant melanoma earlier in life than men, and the death rate from metastases is 31.4 per cent. in women compared with 57.6 per cent. in men. Does some endocrine factor in women check or delay the appearance of metastases, and does such a factor affect the radio-sensitivity of malignant melanoma cells? 
TABLE III

SEX

\begin{tabular}{l|c|c}
\multicolumn{1}{c|}{ Result } & Male & Female \\
\hline Success & 35 & 34 \\
\hline Failure & 10 & 6 \\
\hline Died from metastases & 4 & 2 \\
\hline Uncertain result to date & 6 & 3 \\
\hline \multicolumn{1}{c|}{ Total } & 55 & 45 \\
\hline
\end{tabular}

TABLE IV

Age INCIDENCE

\begin{tabular}{c|c|c}
\hline Decade & Age in Years & No. of Cases \\
\cline { 2 - 3 } & 13 & 1 \\
2 & 14 & 1 \\
3 & $20-30$ & 2 \\
4 & $31-40$ & 16 \\
\hline 5 & $41-50$ & 28 \\
6 & $51-60$ & 29 \\
\hline 7 & $61-70$ & 17 \\
8 & $71-77$ & 5 \\
9 & 84 & 1 \\
\hline & & Total 100 \\
\hline
\end{tabular}

\section{Pregnancy}

During the last decade it has been suggested that pregnancy accelerates cell growth in malignant melanoma and is liable to induce metaplasia in apparently inactive melanomata. Indeed, one patient in this series, aged 33, had her pregnancy ended on the advice of her gynaecologist when he learned that she had had a malignant melanoma of the choroid which had been irradiated two years before she became pregnant. George, Fortner, and Pack (1960), in a critical evaluation of the known physiological processes and in clinical observations of 415 patients at the Memorial Hospital, New York, showed that there was no evidence of increased extension of malignant melanomata of the skin during pregnancy, and that the clinical course of the neoplasm and survival rate were similar in a series of pregnant patients compared with a control group of women who were not pregnant. It is probable that the error arose from the observations from single case reports and not from a comparative study of two series-the one pregnant and the other not. It is, however, true that pregnancy may affect the degree of pigmentation of a melanoma as, indeed, it causes pigmentation in other parts of the body. The majority of women patients with malignant melanoma of the uveal tract are past the age of possible gestation. This fact, and the necessity for immediate treatment, either radical or conservative, make it impossible to assess the effect of pregnancy on a malignant melanoma of the choroid.

Age

The age pattern in this series follows that of any large series of malignant melanoma of the choroid, the majority, 57 patients, being in the fifth and sixth decades of life (Table IV). The youngest was 13 years old and the oldest 84 . Does age have any effect on the response to irradiation? The cases of a boy of 13 with a neoplasm $10 \mathrm{~mm}$. in diameter (Fig. 4) and a girl of 14 with a growth $8 \mathrm{~mm}$. in diameter, and the successes in patients, particularly women, from 31 to 40 years old, show a more rapid reduction of the neoplasm to a flat, pigment-stippled scar than was the case in patients in the fifth and sixth decades of life. Is an apparently malignant melanoma of the uveal tract in adolescents comparable to the so-called juvenile melanoma of 
the skin which, despite having histological features indistinguishable from malignant melanoma, pursues a benign clinical course? Malignant melanoma of the uveal tract is so rare in the young and seemingly so dangerous, that to my knowledge none has dared to watch the clinical behaviour over some years.

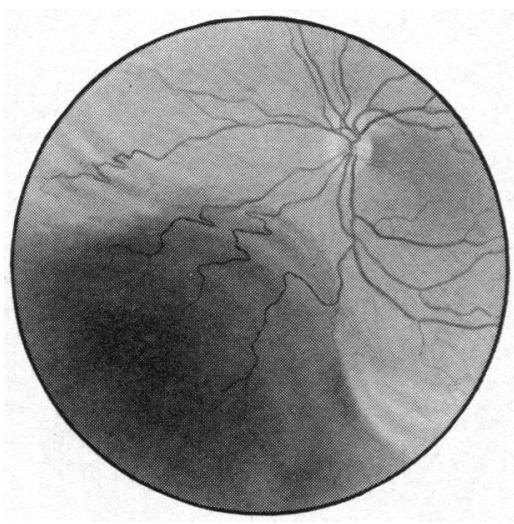

A

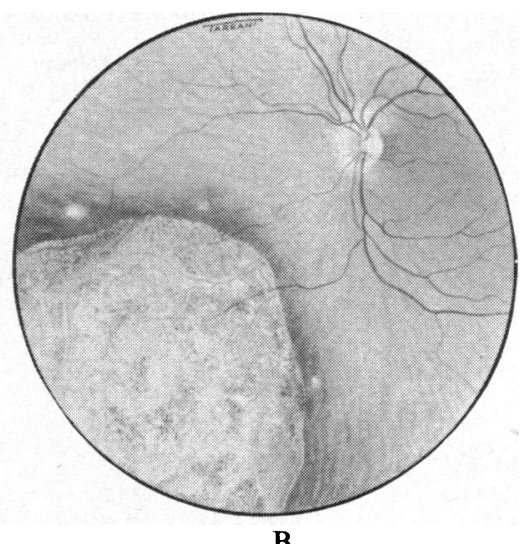

B

FIG. 4.-Malignant melanoma A, before, and B, after irradiation in a boy aged 13 years.

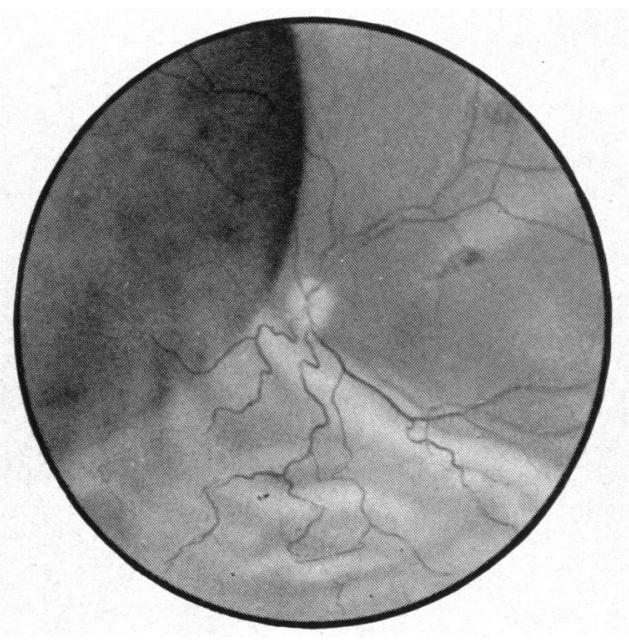

A

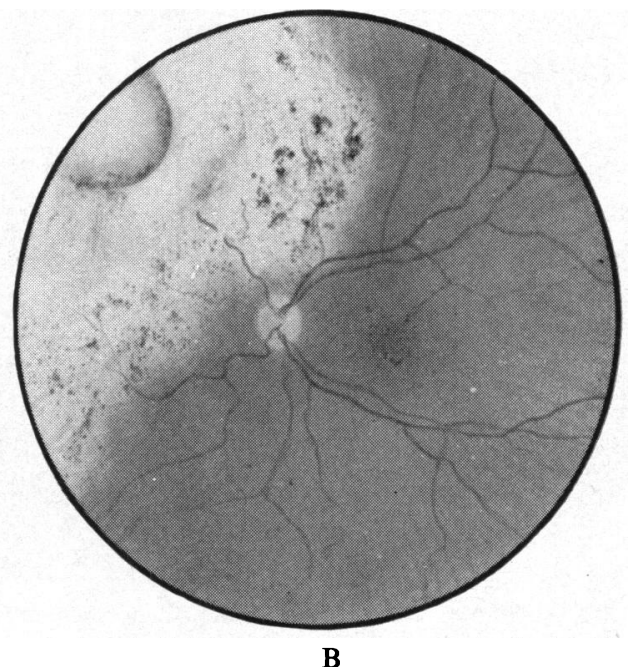

B

FIG. 5.-Apparent destruction of neoplasm which was larger (16 $\mathrm{mm}$. diameter) than those usually successfully treated. A, before, and B, after irradiation.

\section{Size and Site of the Neoplasm}

In the majority of successes the neoplasm measured 5 to $8 \mathrm{~mm}$. in diameter. In three cases with diameters $13 \cdot 5,14$, and $16 \mathrm{~mm}$. respectively, the neoplasm has been apparently destroyed (Fig. 5). The site of the neoplasm in the choroid seemed to be of little consequence to either success or failure after irradiation. 


\section{Results}

To date, 69 patients in this series of 100 have shown post-irradiation recession of the neoplasm to a flat, pigment-stippled scar and attenuation of the retinal vessels in the vicinity (Fig. 6). Seven of these successfully treated patients have died of other diseases, 5 of cardiac failure, one in an air crash, and one of carcinoma of a kidney, seventeen and a half years after successful irradiation of a symmetrical bilateral malignant melanoma of the choroid discovered at the age of 36. In 6 of these (the air-crash fatality excluded) there was no post-mortem evidence of malignant melanoma metastases.

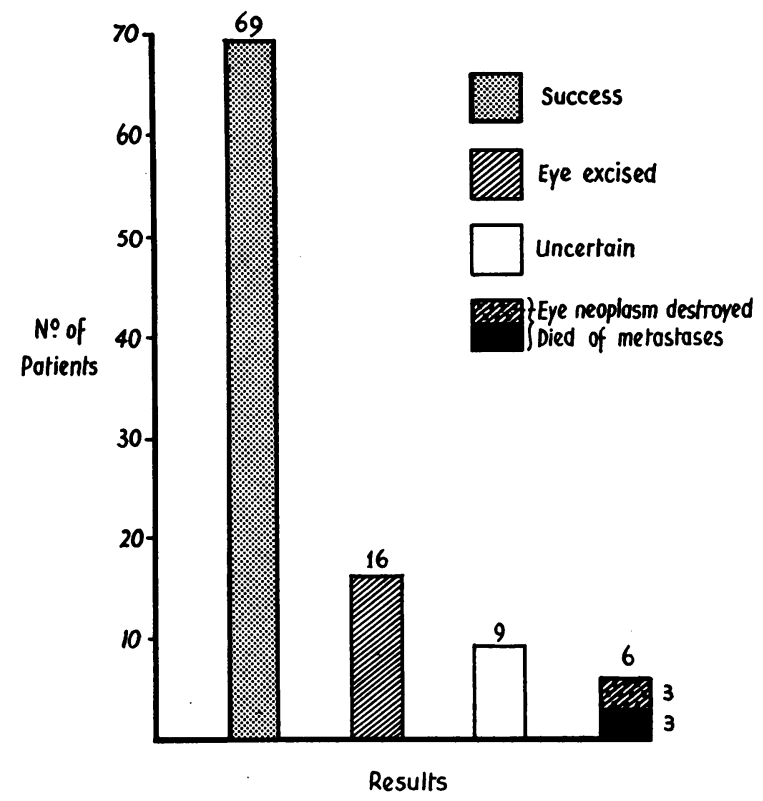

FIG. 6.-Results of malignant melanoma of choroid treated by radio-active applicators in 100 patients, 1939-64.

Sixteen patients had the irradiated eye excised because it was doubtful whether the neoplasm had been destroyed. In the light of later experience it was evident that in three of these a wait of two months after irradiation is inadequate time in which to assess the effect of treatment, and it would seem proper to wait for four to six months, provided that the neoplasm is not growing during this period of post-irradiation observation.

Six patients have died of metastases and in three of these there was no evidence of active malignant melanoma in their irradiated eyes. In one patient such a fate was inevitable, for extra-ocular extension was evident on exposing the sclera to apply a radio-active disc. She had had cerebral vascular episodes and lived two years after treatment, with useful vision. The other two patients had large neoplasms, one occupying nearly the lower half of the eye and the other being $14 \mathrm{~mm}$. in diameter on the nasal side. These patients had $6 / 36$ and $6 / 18$ vision respectively until death two years and one and a half years respectively after irradiation. It is doubtful whether excision of the eye in these six patients would have saved their lives. 
In nine patients the result remains uncertain to date. The neoplasm has receded, but there remains a raised-mass in the centre, partly translucent on account of cell debris but possibly containing malignant melanoma cells in a damaged state, incapable of cell division to date but nevertheless a potential danger. In two of these the Geiger count test was negative, but this cannot be taken as infallible.

\section{Light Coagulation}

Light coagulation as an alternative conservative treatment has certain limitations in respect of the site and size of a malignant melanoma. It is dangerous to use it on a neoplasm adjacent to the optic disc because of damage to the optic nerve and to the large branches of the central retinal vessels. Circumvallation by light coagulation of a neoplasm near the macula will either mar or destroy central vision. Moreover, effective destruction of neoplastic cells is limited with each treatment to a depth of $2 \mathrm{~mm}$. only. The retina overlying a malignant melanoma is intact, although degenerate, but light coagulation may so destroy the retina that the neoplasm bursts forward in direct contact with the vitreous. So it would seem that this treatment is likely to be effective only in small neoplasms between large retinal vessels and not in those adjacent to the optic disc and the macula. Several treatments may be necessary to effect destruction of the neoplasm. Light coagulation is of value when combined with radiotherapy in treating the summit of a malignant melanoma which may not receive the effective dose that has successfully destroyed the base and much of its mass, and it is also helpful in treating any residual pigmented debris suspected of harbouring potentially active cells.

\section{Partial Choroidectomy}

When irradiation failed in an only eye partial choroidectomy was done for two patients. The exposure is technically the same as for partial cyclectomy. It is less difficult, and I think safer, if a lamella of sclera is left over the base of the neoplasm. It is possible to complete this operation without loss of vitreous and to keep the outer surface of the stippled retinal pigment epithelium intact.

\section{Complications}

The commonest complication was perimacular exudates, which occurred in 11 patients in this series and became evident from five months to seven and a half years, the majority from two to three years, after irradiation of a neoplasm near the macula and optic disc. It was commoner in women (7) than men (4). Seven patients had received one radio-active application and 4 two applications. In 5, all women, the pattern of the exudates resembled circinate retinopathy. Absorption of the exudates has been slow and has taken more than three years.

Punctate retinal haemorrhages in and adjacent to the irradiated area are often associated with a telangiectatic state of the small arterioles. These occurred in 9 patients who had received one radio-active application and appeared from five months to fifteen years, the majority between two and three years, after irradiation. Vitreous haemorrhages occurred in 3 patients after one radio-active application and slowly absorbed. 
Irradiation cataract occurred in 7 patients, 4 of whom were men and 3 women, and their ages were between 12 and 51 years. In 3 the opacities were central in the posterior cortex and were limited to an area about 1-1.5 mm., and in two of these the opacities appeared one year and nine months after irradiation. In two other patients the opacities were sectorial and arose at the equator in the quadrant of the lens nearest the neoplasm. In these five there has been no increase in the extent of the opacities. The two remaining patients have shown a slow increase in the opacities affecting the posterior cortex. The appearance of the lens opacities was from two and a half years to seven years and nine months after irradiation. The site of the irradiated neoplasm was adjacent to the optic disc in 2 patients, close to it in one, and about the equator in 4 . Five patients had received one application of ${ }^{60} \mathrm{Co}$, a dose of $30,000-40,000 \mathrm{r}$ at the base and 10,000-14,000 $\mathrm{r}$ at the summit, and $2 \mathrm{had}$ had two applications amounting to about $80,000 \mathrm{r}$ at the base and $28,000 \mathrm{r}$ at the summit of the neoplasm.

Partial scleral sloughing 3-4 mm. in diameter occurred in 2 patients over the site of a large neoplasm which required the application of a 15-mm. active diameter applicator with $2.9 \mathrm{mc} .{ }^{60} \mathrm{Co}$. In one the defect was repaired by a lamellar corneal graft and in the other by a doubly folded piece of fascia lata. Two patients had complicated glaucoma which developed two years after irradiation. Superficial punctate keratitis occurred in 2 patients one year and three years respectively after two treatments with the $15-\mathrm{mm}$. active diameter $2.9 \mathrm{mc} .{ }^{60} \mathrm{Co}$ applicator.

\section{Visual Results}

Table $\mathrm{V}$ shows the visual results. The relatively large number of patients (38) with poor vision from $6 / 18$ to less than $6 / 60$ is due to the proximity of the neoplasm to the macula and the optic disc and to the late appearance of petechial haemorrhages and circinate exudates in the papillo-macular area.

\begin{tabular}{c|c}
\multicolumn{2}{c}{ TABLE V } \\
\multicolumn{2}{c}{ Vision } \\
\hline Vision & No. of Patients \\
\hline $6 / 5$ & 6 \\
\hline $6 / 6$ & 11 \\
\hline $6 / 9$ & 7 \\
\hline $6 / 12$ & 7 \\
\hline $6 / 18$ & 7 \\
\hline $6 / 24$ & 1 \\
\hline $6 / 36$ & 6 \\
\hline $6 / 60$ & 8 \\
\hline$<6 / 60$ & 16 \\
\hline
\end{tabular}

\section{Conclusion}

It is evident that some malignant melanomata of the choroid are destroyed by the application of a radio-active applicator sutured to the sclera precisely over the base of the neoplasm. The results are encouraging when the neoplasm is $8 \mathrm{~mm}$. or less in diameter and has not burst through Bruch's membrane. The prognosis after such treatment is better in women and adolescents than in men. 
I am grateful to Dr. Peter Hansell of the Medical Illustration Department of the Institute of Ophthalmology, and to Mr. Tredinnick, in charge of the Medical Illustration Department at St. Bartholomew's Hospital, for much help with the illustrations.

\section{REFERENCES}

George, P. A., Fortner, J. G., and Pack, G. T. (1960). Cancer (Philad.), 13, 854.

MACRAE, A. (1953). Trans. ophthal. Soc. U.K., 73, 3.

STAllard, H. B. (1933). "Radiant Energy as (a) a pathogenic, (b) a therapeutic agent in ophthalmic disorders". Brit. J. Ophthal., Monograph Supplement 6. (1949). Trans. ophthal. Soc. U.K., 69, 293. (1959). Ibid., 79, 373.

(1961). Ann. roy. Coll. Surg. Engl., 29, 170.

(1964). European Congress of Ophthalmology (in the press). 